\title{
Effect of Suo Quan Wan on the bladder function of aging rats based on the $\beta$-adrenoceptor
}

\author{
YI-FEI XU $^{1 *}$, ZHI-JIAN LIANG $^{1 *}$, ZHAO-JIN KUANG $^{1}$, JIE-JUN CHEN ${ }^{2}$, JUN WU $^{3}$, XIANG-E LU ${ }^{4}$, \\ WEI-WEN JIANG ${ }^{1}$, PING-LONG FAN ${ }^{1}$, LI-YAO TANG ${ }^{1}$, YI-TAO LI ${ }^{1}$, PING HUANG ${ }^{1}$ and HONG-YING CAO ${ }^{1}$ \\ ${ }^{1}$ Department of Chinese Medicine Pharmacology, School of Chinese Materia Medica, Guangzhou University \\ of Chinese Medicine, Guangzhou, Guangdong 510006; ${ }^{2}$ Center for Drug Non-Clinical Evaluation and Research, \\ Guangzhou General Pharmaceutical Research Institute, Guangzhou, Guangdong 510240; ${ }^{3}$ Department of Chinese Medicine, \\ School of Chinese Medicine, Shandong College of Traditional Chinese Medicine, Yantai, Shandong 264199; \\ ${ }^{4}$ Department of Traditional Chinese Medicine, Institute of Traditional Chinese Medicine, \\ Guangdong Pharmaceutical University, Guangzhou, Guangdong 510006, P.R. China
}

Received December 25, 2015; Accepted February 7, 2017

DOI: $10.3892 /$ etm.2017.4394

\begin{abstract}
Suo Quan Wan (SQW) has been used to treat lower urinary tract symptoms (LUTS) in elderly patients for hundreds of years in China. $\beta$-adrenoceptors ( $\beta$-ARs), particularly $\beta_{3}$-adrenoceptor $\left(\beta_{3}\right.$-AR), was reported to be important in the bladder dysfunction of the elderly. The present study was conducted to explore the effect of $\beta$-AR, and particularly the $\beta_{3}$-adrenoceptor, in aging rat bladder function in vitro and to test the therapeutic effect of SQW on LUTS in an aging rat model based on the $\beta_{3}$-adrenoceptor. Briefly, the bladder
\end{abstract}

Correspondence to: Professor Hong-Ying Cao, Department of Chinese Medicine Pharmacology, School of Chinese Materia Medica, Guangzhou University of Chinese Medicine, Higher Education Mega Center, 232 Wai Huan East Road, Guangzhou, Guangdong 510006, P.R. China

E-mail: yueerhy@yahoo.com

${ }^{*}$ Contributed equally

Abbreviations: SQW, Suo Quan Wan; LUTS, lower urinary tract symptoms; AR, adrenoceptor; ISO, isoprenaline; $\mathrm{E}_{\max }$, effect of maximum relaxation; IA, intrinsic activity; $\mathrm{EC}_{50}, 50 \%$ effective concentration; $\mathrm{PD}_{2}, \log \left(\mathrm{EC}_{50}\right) ; \mathrm{PA}_{2}$, intensity of competitive antagonist; MBC, maximum bladder capacity; BP, bladder leak point pressure; EV, efficiency of voiding; MUP, maximum urethral pressure; MUCP, maximum urethral closure pressure; FUL, functional urethral length; MVP, maximum voiding pressure; PVR, post-void residual; BC, bladder capacity; ALPP, abdomen leak point pressure; VV, voiding volume; AVPR-V2, vasopressin type 2 receptor; AQP-2, aquaporin-2; ALD, aldosterone; TLC, thin-layer chromatography; HPLC, high-performance liquid chromatography; $\mathrm{SD}$, standard deviation; RT-qPCR, reverse transcription-quantitative polymerase chain reaction

Key words: Suo Quan Wan, aging rat, $\beta$-adrenoceptor, bladder detrusor, bladder dysfunction detrusor muscles of young (age, 3 months) and aging (age, 15 months) female rats were separated. A $\beta$-AR non-selective agonist, isoprenaline (ISO), subtype $\beta_{3}$-AR agonist (BRL37344A) and $\beta_{3}$-AR antagonist (SR59230A) were used to define the tension change of detrusor muscles between young and aging rats in vitro. For blank controls, 12 young rats were marked, and 48 aging female rats were randomly divided into four groups as follows: Model, SQW high, SQW middle and SQW low. Following oral administration of SQW for 6 weeks in aging rats, urodynamic and bladder detrusor tests were used to evaluate the therapeutic effect of SQW. The expression of $\beta_{3}$-AR mRNA was investigated using reverse transcription-quantitative polymerase chain reaction. Using ISO and BRL37344A in vitro, maximum relaxation $\left(\mathrm{E}_{\max }\right)$, intrinsic activity (IA), and log (50\% effective concentration) $\left(\mathrm{PD}_{2}\right)$ were significantly decreased in aging rats compared with that in young rats $(\mathrm{P}<0.05)$. Significant changes were also observed in the $\beta_{3}$-AR antagonist experiment, which blocked ISO-induced relaxation, with significant decreases observed in $\mathrm{E}_{\max }, \mathrm{IA}$ and $\mathrm{PD}_{2}$, and a significant increase observed in $\mathrm{PA}_{2}$ for the aging rats compared with the young controls $(\mathrm{P}<0.05)$. SQW was demonstrated to enhance bladder control, storage and contraction ability. Furthermore, SQW was able to increase the sensitivity and expression of $\beta_{3}$-AR in an aging rat. In conclusion, the decrease in $\beta_{3}$-AR sensitivity in aging rats and the expression resulted in bladder detrusor dysfunction. In addition, the therapeutic effect of SQW against LUTS relies on the former's effect on the urethral sphincter, bladder detrusor and $\beta_{3}$-AR.

\section{Introduction}

With increasing age, urinary urgency, with or without incontinence, and nocturia becomes a common problem to the elderly (1). The aging process affects bladder function and is a notable factor in the degeneration of the urinary tract smooth muscle. According to a urodynamic test, the maximum bladder capacity (MBC) in elderly people 
( $>60$ years old) is reported to be higher than that in younger people ( 40 years old), whereas the bladder leak point pressure (BP), efficiency of voiding (EV), maximum urethral pressure (MUP), maximum urethral closure pressure (MUCP) and functional urethral length (FUL) are reported to decrease during the aging process $(2,3)$. Evidence indicates that $40 \%$ of 60 -year-old women have lower urinary tract symptoms (LUTS), and epidemiological research reveals that advancing age is one of the major risk factors of LUTS (4). The current medicinal treatment of LUTS is based on available antimuscarinic agents, including oxybutynin and tolterodine. Although treatment of LUTS with these agents may be effective, their usage may lead to cognitive decline (5).

The urine storing and voiding function is based on the contractile and relaxant system of the bladder. Muscarinic receptors are the bladder's most important contractile system, whereas $\beta$-adrenoceptor $(\beta$-AR) is its most important relaxant (6). Given that the quantity and affinity of muscarinic receptors in the bladder do not change with aging, the declining number and lower sensitivity of the $\beta$-AR appears to be the major pathological factor in an aging bladder (7). Three subtypes of $\beta$-AR exist, namely, $\beta_{1}$-AR, $\beta_{2}$-AR and $\beta_{3}$-AR. The detrusor relaxant is primarily mediated via $\beta_{3}$-AR (8-10). In the present study, an in vitro organ bath study was used to test the change in $\beta_{3}$-AR in aging rats.

Suo Quan Wan (SQW) is an ancient Chinese formula which consists of Lindera aggregata (Sims) Kosterm., fructus; Alpinia oxphylla Miq., radix; and Dioscorea opposita Thunb., rhizome, and has been widely used in China by people suffering from nocturnal enuresis, frequent or urgent urination. Recently, novel indications of SQW have been reported, such as in enuresis in children $(11,12)$, non-urinary tract infection in elderly patients (13) and chronic prostatitis (14). Research has been conducted to determine the possible mechanism of SQW. Previous studies by the present authors have revealed that SQW is able to upregulate the expression of AVPR-V2 and AQP-2 (15). It has also been reported that SQW is able to regulate the synthesis of ALD (16). However, the correlation between SQW and aging-related LUTS remains unknown. Therefore, the present study aimed to investigate the effect of $\beta_{3}-\mathrm{AR}$ in an aging bladder and to determine whether SQW has an effect on $\beta_{3}$-AR.

\section{Materials and methods}

Reagents. SQW was purchased from Hunan Hansen Pharmaceutical Co., Ltd. (Yiyang, China; lot no. 110602). Three plants were weighed in a ratio of $1: 1: 1$, crushed into powder and then mixed evenly. Appropriate volumes of distilled water were used to make these powders into pills. According to the Chinese Pharmacopeia (17), assurance of quality control for SQW was validated, and linderane was the recorded reference standard of SQW. HPLC (data not shown) and TLC methods were used to test these SQW chemicals (18). Based on clinical usage, the Bios method (19) was used to calculate the equivalent dose, and this result was used as a middle dose ( $0.585 \mathrm{~g} / \mathrm{kg} /$ day). Low $(0.293 \mathrm{~g} / \mathrm{kg} /$ day $)$ and high $(1.170 \mathrm{~g} / \mathrm{kg} /$ day $)$ doses were defined as a half and double of the equivalent dose, respectively.
Ethyl carbamate was purchased from Sinopharm Chemical Reagent Co., Ltd. (Shanghai, China; lot no. T20090312); isoprenaline (ISO) was obtained from Shanghai Harvest Pharmaceutical Co., Ltd. (Shanghai, China; lot no. 110102); BRL37344 was obtained from Tocris Bioscience (Bristol, UK; lot no. 4A/110044); SR59230A was obtained from Sigma-Aldrich (Merck KGaA, Darmstadt, Germany; lot no. 010M4613 V); $\mathrm{NaCl}$ (lot no. 2010308), $\mathrm{KCl}$ (lot no. 20050905), $\mathrm{MgSO}_{4}$ (lot no. 2010315), $\mathrm{KH}_{2} \mathrm{PO}_{4}$ (lot no. 2010320), $\mathrm{NaHCO}_{3}$ (lot no. 20100129), $\mathrm{C}_{6} \mathrm{H}_{12} \mathrm{O}_{6}$ (lot no. 2011314) and $\mathrm{CaCl}_{2}$ (lot no. 2007328) were purchased from Tianjin Damao Chemical Reagent Factory (Tianjin, Tianjin Province, China). Chloroform (lot no. 20130601) and isopropanol (lot no. 20130410) were purchased from Guangzhou Chemical Reagent Factory (Guangzhou, China). In addition, all reagents used were of analytical grade.

Animals. A total of 12 young Sprague-Dawley female rats (age, 3 months) weighing 240-280 g and 48 aging Sprague-Dawley female rats (age, 15 months) weighing 320-400 g, provided by the Laboratory Animal Center of Guangzhou University of Chinese Medicine (Guangzhou, China) were used in the present study. All rats were group-housed in cages at a temperature of $24 \pm 2^{\circ} \mathrm{C}$ with humidity of $50-70 \%$, ad libitum access to food and water and a 12-h light/dark cycle. The trial was approved by Animal Experimental Ethical Inspection of Guangzhou University of Chinese Medicine.

\section{Change of $\beta$-AR function in aging rats}

General preparations. After being acclimated to laboratory conditions for 1 week, young and aging female rats (12 rats from each group) were sacrificed by $\mathrm{CO}_{2}$ asphyxiation. Their bladders were isolated and placed in Krebs solution containing $118 \mathrm{mmol} / 1 \mathrm{NaCl}, 4.75 \mathrm{mmol} / 1 \mathrm{KCl}, 1.18 \mathrm{mmol} / 1 \mathrm{MgSO}_{4}$, $1.18 \mathrm{mmol} / 1 \mathrm{KH}_{2} \mathrm{PO}_{4}, 24.8 \mathrm{mmol} / 1 \mathrm{NaHCO}_{3}, 10.0 \mathrm{mmol} / \mathrm{l}$ $\mathrm{C}_{6} \mathrm{H}_{12} \mathrm{O}_{6}$, and $2.5 \mathrm{mmol} / 1 \mathrm{CaCl}_{2}$ (pH 7.40). After removing the vertex of each bladder, the mucosa, and the organization below the mucosa, the body of the bladder was longitudinally opened. An 8x3 mm detrusor strip was harvested and suspended in a bath (cat. no. ML0126/10; ADInstruments Pty, Ltd., Bella Vista, Australia) containing Krebs solution at $37^{\circ} \mathrm{C}$ and continuously supplied with a mixture of $\mathrm{O}_{2}(95 \%)$ and $\mathrm{CO}_{2}$ (5\%). The detrusor strip was connected to a tension sensor (cat. no. MLT0210/D; ADInstruments Pty, Ltd.), which was linked to a biological signal amplifier (cat. no. ML221; ADInstruments Pty, Ltd.). The tension generated by the detrusor strip was measured and recorded using an eight-channel biological function recording system (cat. no. ML870; ADInstruments Pty, Ltd.). Prior to the experiment, the detrusor strips were stabilized for $30 \mathrm{~min}$ in a bath containing Krebs solution.

Role of the $\beta$-AR in detrusor strip relaxation. Following adjusting the detrusor strip to a tension of $1.0 \mathrm{~g}$, the strip was stabilized for $30 \mathrm{~min}$. Thereafter, $\mathrm{KCl}$ was added in the bath to a final concentration of $40 \mathrm{mmol} / 1$ before reaching an equilibrium state in $30 \mathrm{~min}$, and the strip tension was recorded (20-22). According to the cumulative concentration effect experiment (23), ISO, which is a $\beta$-AR agonist, was cumulatively added into the bath to final concentrations of $10^{-10}, 10^{-9}, 10^{-8}, 10^{-7}, 10^{-6}, 10^{-5}$ and $10^{-4} \mathrm{M}$, with a 5 -min interval 
for each concentration, and the tension under each ISO concentration was recorded. The process was repeated thrice, and the mean reading was taken. In addition, the detrusor strip was washed and stabilized with Krebs solution at $37^{\circ} \mathrm{C}$ prior to each experiment. The following formula was used for the calculations of the effect of maximum relaxation $\left(\mathrm{E}_{\max }\right)$ :

$\mathrm{E}_{\max }=(\mathrm{NC}-\mathrm{NX}) / \mathrm{NCx} 100 \%$, where $\mathrm{NC}$ is the tension prior to adding ISO, $\mathrm{NX}$ the tension after adding agonist and $\mathrm{E}_{\max }$ is the percentage of the tension under the maximum ISO concentration and initial tension.

In addition, the intrinsic activity (IA) was calculated using the following formula:

$$
\mathrm{IA}=\mathrm{E}_{\max }(\text { experimental group}) / \mathrm{E}_{\max } \text { (control group) }
$$

Furthermore, $50 \%$ effective concentration $\left(\mathrm{EC}_{50}\right.$ ) was calculated based on the cumulative concentration effect curve determined by Powerlab in LabChart version 8 software (ADInstruments Pty, Ltd.) and was presented as the following equation: $\mathrm{PD}_{2}=-\log \left(\mathrm{EC}_{50}\right)$. All data were presented using Powerlab software.

Relaxation effect of the $\beta_{3}$-AR agonist on the detrusor strip. The method used was the same as the test for the role of $\beta$-AR in detrusor strip relaxation. The $\mathrm{E}_{\max }, \mathrm{IA}$, and $\mathrm{PD}_{2}$ values of the $\beta_{3}$-AR agonist (BRL37344) were determined.

$\beta_{3}$-AR antagonist blocked the ISO-caused relaxation in the detrusor strip. The detrusor strip was adjusted to a tension of $1.0 \mathrm{~g}$ and stabilized for $30 \mathrm{~min}$ in the bath. $\mathrm{KCl}$ was added to a final concentration of $40 \mathrm{mmol} / \mathrm{l}$, which was stabilized for $30 \mathrm{~min}$. Afterwards, the detrusor strip tension was recorded (24). The $\beta_{3}$-AR antagonist SR59230A was added into the bath to concentrations of $0,10^{-7}, 10^{-6}$ and $10^{-5} \mathrm{M}$. Under each concentration of SR59230A, the ISO was cumulatively added into the bath to concentrations of $10^{-10}, 10^{-9}, 10^{-8}, 10^{-7}$, $10^{-6}, 10^{-5}$ and $10^{-4} \mathrm{M}$, with a 5 -min interval for each ISO concentration, and the tension of each ISO concentration was recorded. The strip was washed and stabilized with Krebs solution at $37^{\circ} \mathrm{C}$ between each concentration of SR59230A. The $\mathrm{PD}_{2}$ value of ISO under each concentration of SR59230A was determined by Powerlab software, and a concentration-effect curve was obtained.

The detrusor strip was adjusted to a tension of $1.0 \mathrm{~g}$, and the cumulative concentration effect experiment on ISO was performed. After the maximum relaxant effect was obtained, the strip was washed and incubated in Krebs solution at a temperature of $37^{\circ} \mathrm{C}$ until equilibrium was reached. SR59230A was added at $10^{-6} \mathrm{M}$ into the bath, and the cumulative concentration effect experiment of ISO was repeated. $\mathrm{E}_{\max }, \mathrm{IA}, \mathrm{PD}_{2}$ and $\mathrm{PA}_{2}$ values were then compared. In the following formula (25) $\mathrm{PA}_{2}$ denotes the intensity of competitive antagonist:

$$
\begin{aligned}
& \mathrm{PA}_{2}=-\log [\mathrm{X}] \\
& \mathrm{X}=10^{-\mathrm{PD} 2 \text { (After) }} / 10^{-\mathrm{PD} 2 \text { (Before) }}
\end{aligned}
$$

\section{Effect of SQW on urodynamic change in aging rats}

General preparations. After being acclimated to laboratory conditions for 1 week, young rats were marked as a blank control $(n=12)$, whereas aging rats were randomly divided into
4 groups ( $n=12$ in each), including the model group (administered water) and the groups that were administered with low, middle and high dosages of SQW. Water and SQW was administrated orally, once daily for 6 weeks.

Urodynamic test. Rats were administered anesthesia intraperitoneally using $10 \%$ ethyl carbamate $(0.8 \mathrm{~g} / \mathrm{kg})$, and their bladders were emptied. A bladder piezometric and water infusion tube that was connected with a WZ-50C6 microinjection pump [cat. no. WZ-50C6; Smiths Medical Instrument (Zhejiang) Co., Ltd., Hangzhou, Zhejiang Province, China] was inserted into the urethra of the rats. The abdominal pressure tube was inserted $4 \mathrm{~cm}$ into the rectum, and the bladder piezometric tube, microinjection pump and abdominal pressure tube were connected to the urodynamic detector (cat. no. 94-R01-BT; Delphis; Laborie, Mississauga, ON, Canada) (26).

Normal saline was infused into the bladder at a speed of $0.5 \mathrm{ml} / \mathrm{min}$, and the infusion was stopped if leaking from the urethra was observed. BP, maximum voiding pressure (MVP), FUL, MUP and MUCP were then measured. In addition, the post-void residual (PVR) was recorded using a $1 \mathrm{ml}$ injector to collect the remaining urine in the bladder. The $\mathrm{MBC}$, voiding volume (VV), EV and bladder capacity (BC) were calculated using the following formula:

MBC=infusion time $x$ infusion speed
VV=MBC-PVR
EV=VV/MBC
$B C=M B C / B P$

Normal saline was again infused into the bladder, and the epigastrium was gently pressed via the Valsalva method (27) when the injection volume in the bladder reached half of the MBC. The pressure was recorded as the abdomen leak point pressure (ALPP) if leaking from the urethra was observed. Furthermore, the entire process was repeated twice, and the mean of each parameter was determined.

Effect of $S Q W$ on the $\beta$-AR in aging rats. Following the urodynamic test, rats were sacrificed by $\mathrm{CO}_{2}$ asphyxiation, and the detrusor strips were harvested and used for the $\beta$-AR function test detailed above.

Effect of $S Q W$ on $\beta_{3}$-AR mRNA expression. Following sacrifice, $40 \mathrm{mg}$ of bladder tissue was isolated to quantify $\beta_{3}$-AR mRNA using reverse transcription-quantitative polymerase chain reaction (RT-qPCR). RNA extraction was performed using TRIzol reagent (Thermo Fisher Scientific, Inc., Waltham, MA, USA), according to the manufacturer's instructions. Briefly, samples were homogenized, incubated at room temperature for $5 \mathrm{~min}$, and $0.2 \mathrm{ml}$ chloroform per $1 \mathrm{ml}$ TRIzol was added. Following centrifugation at $12,000 \mathrm{xg}$ for $10 \mathrm{~min}\left(4^{\circ} \mathrm{C}\right)$, the supernatants were removed to a new tube and a 2-fold volume of isopropanol was added to precipitate the mRNA. Subsequent to freeze centrifugation, the mRNA precipitation was dissolved in RNase-free water. The mRNA concentration was measured at an absorbance of $260 \mathrm{~nm}$, and the purity was evaluated via the $\mathrm{A}_{260} / \mathrm{A}_{280}$ ratio (BioSpec-nano; Shimadzu Corp., Kyoto, Japan). mRNA samples $(1 \mu \mathrm{g})$ were then used for the RT reaction 
using a RevertAid First Strand cDNA Synthesis kit (Thermo Fisher Scientific, Inc.), according to the manufacturer's instructions. The RT reaction was performed at $42^{\circ} \mathrm{C}$ for $1 \mathrm{~h}$ and $70^{\circ} \mathrm{C}$ for $5 \mathrm{~min}$. In addition, a Maxima SYBR-Green/ROX qPCR Master Mix kit (Thermo Fisher Scientific, Inc.) was used for qPCR, according to the manufacturer's instructions. The primers used were as follows: $\beta_{3}$-AR forward, 5'-GGG CCACATTGGCGCTGACT-3' and reverse, 5'-TGGGTGTCC CGACTGT-3'; and GAPDH forward, 5'-TGCTGGGGCTGG CATTGCTC-3' and reverse, 5'-CCCCAGGCCCCTCTGTTG $\mathrm{T}-3^{\prime}$. In addition, the cycle profile was set to $95^{\circ} \mathrm{C}$ for $15 \mathrm{sec}$; $60^{\circ} \mathrm{C}$ for $30 \mathrm{sec} ; 72^{\circ} \mathrm{C}$ for $15 \mathrm{sec}$ and for 40 cycles. Data were then analyzed using the 7500 Real-Time PCR System software version 2.0.6 (ABI 7500; Applied Biosystems; Thermo Fisher Scientific, Inc.), and the results were quantified using the $2^{-\Delta \Delta C q}$ method (28).

Statistical analysis. Data are presented as the mean \pm standard deviation and were analyzed using a one-way analysis of variance for multiple experiment groups. All statistical analyses were performed with SPSS 19.0 software (IBM SPSS, Armonk, NY, USA). $\mathrm{P}<0.05$ was considered to indicate a statistically significant difference.

\section{Results}

\section{Bladder detrusor change in aging rats}

Relaxant effect of the $\beta$-AR agonist ISO on the detrusor strip. As shown in Table I, significantly lower $\mathrm{E}_{\max }$, IA and $\mathrm{PD}_{2}$ values were observed in aging rats compared with young controls. Given that $\mathrm{PD}_{2}$ represents the affinity between an agonist and a receptor, this result indicated the lower sensitivity and affinity of the detrusor receptor to the $\beta$-AR agonist in aging rats.

Effect of the $\beta_{3}$-AR agonist BRL37344 on the relaxation of detrusor strip. As shown in Table II, the $\mathrm{E}_{\max }$, IA and $\mathrm{PD}_{2}$ of the $\beta_{3}$-AR agonist in the model group were significantly lower than those in the young control group, indicating that the sensitivity or the number of $\beta_{3}$-AR was significantly decreased in aging rats.

Influence of subtype $\beta_{3}$-AR SR59230A antagonist on the detrusor strip. As the concentrations of the $\beta_{3}$-AR antagonist increased, the $\mathrm{PA}_{2}$ values of ISO markedly increased, whereas the $\mathrm{PD}_{2}$ values decreased (Table III). This observation indicated the blocking effect of the $\beta_{3}$-AR antagonist on ISO-induced relaxation in the detrusor strip.

As shown in Table IV, in the presence of SR59230A, $\mathrm{E}_{\max }$, $\mathrm{IA}$, and $\mathrm{PD}_{2}$ of ISO in aging rats were significantly lower than those of ISO in young controls. However, $\mathrm{PA}_{2}$ was significantly higher in the aging rats in comparison to the value in the young controls. These results indicated that less $\beta_{3}$-AR antagonist was recruited to reach the same antagonistic level in aging rats, as compared with young rats.

\section{Effect of $S Q W$ in aging rats}

Effect of $S Q W$ on ISO-induced relaxant on the detrusor strip. As shown in Table $\mathrm{V}$, significantly lower $\mathrm{E}_{\max }$, IA and $\mathrm{PD}_{2}$ values were observed in aging rats in the model group compared with the young control group. Following
Table I. Relaxant effect of isoprenaline on detrusor strip.

\begin{tabular}{lccc}
\hline Group & $\mathrm{E}_{\max }$ & $\mathrm{IA}$ & $\mathrm{PD}_{2}$ \\
\hline $\begin{array}{l}\text { Young } \\
\text { controls }\end{array}$ & $62.69 \pm 8.23$ & $0.97 \pm 0.13$ & $6.17 \pm 0.31$ \\
$\begin{array}{l}\text { Model group } \\
\text { (aging rats) }\end{array}$ & $52.59 \pm 7.99^{\mathrm{a}}$ & $0.81 \pm 0.12^{\mathrm{a}}$ & $5.59 \pm 0.32^{\mathrm{a}}$ \\
\hline
\end{tabular}

Data are expressed as mean \pm standard deviation, $n=12$. ${ }^{\mathrm{a}} \mathrm{P}<0.01$ vs young controls. $\mathrm{E}_{\max }$, effect of maximum relaxation; IA, intrinsic activity; $\mathrm{PD}_{2}, \log (50 \%$ effective concentration).

Table II. Influence of BRL37344 on detrusor strip relaxation.

\begin{tabular}{lccc}
\hline Group & $\mathrm{E}_{\max }$ & $\mathrm{IA}$ & $\mathrm{PD}_{2}$ \\
\hline $\begin{array}{l}\text { Young } \\
\text { controls }\end{array}$ & $33.70 \pm 11.12$ & $0.50 \pm 0.17$ & $6.28 \pm 0.66$ \\
$\begin{array}{l}\text { Model group } \\
\text { (aging rats) }\end{array}$ & $25.19 \pm 7.81^{\mathrm{a}}$ & $0.39 \pm 0.12^{\mathrm{a}}$ & $5.71 \pm 0.56^{\mathrm{a}}$ \\
\hline
\end{tabular}

Data are expressed as mean \pm standard deviation, $\mathrm{n}=12$. ${ }^{\mathrm{a}} \mathrm{P}<0.05$ vs. young control. $\mathrm{E}_{\max }$, effect of maximum relaxation; IA, intrinsic activity; $\mathrm{PD}_{2}, \log (50 \%$ effective concentration).

administration, the middle and high doses of SQW significantly reversed this decrease.

Effect of SQW on BRL37344-induced relaxant on the detrusor strip. As shown in Table VI, compared with young controls, a significant decrease in $\mathrm{E}_{\max }$, IA and $\mathrm{PD}_{2}$ of BRL37344 was observed in the model group. These decreases were significantly reversed by administration of SQW.

Effect of SQW on SR59230A-induced inhibition on detrusor strip. As shown in Table VII, following the administration of SR59230A $\left(10^{-6} \mathrm{M}\right)$, the inhibitory effect of the model group was significantly higher than that of the young control. Compared with the model group, the $\mathrm{PA}_{2}$ of the middle- and high-dose SQW groups was significantly decreased.

Effect of $S Q W$ on bladder function in aging rats. As shown in Fig. 1A-D, prior to administration of SQW, the BP, ALPP EV and MVP values of the model group were significantly lower than those of the young controls, and no significant difference was observed between the model and SQW groups. Following administration for 6 weeks, the BP, ALPP, EV and MVP of rats in the three SQW groups significantly increased compared with the model group. In addition, the three dosages of SQW were able to significantly raise BP, ALPP, EV and MVP levels compared with levels prior to SQW administration.

As shown in Fig. $1 \mathrm{E}$ and F, prior to $\mathrm{SQW}$ administration, $\mathrm{MBC}$ and $\mathrm{VV}$ in the model group were significantly higher than those in the young control group, and no difference was shown in MBC and VV between the model and SQW groups. Following administration for 6 weeks, the three dosages of 
Table III. Blocking effect of SR59230A in different concentrations on isoprenaline-induced relaxation in the detrusor strip.

\begin{tabular}{lcccr}
\hline Metric & $0 \mathrm{M}$ & $10-7 \mathrm{M}$ & $10-6 \mathrm{M}$ & $10-5 \mathrm{M}$ \\
\hline $\mathrm{PD}_{2}$ & $6.230 \pm 0.296$ & $5.513 \pm 0.067^{\mathrm{a}}$ & $5.051 \pm 0.058^{\mathrm{a}, \mathrm{b}}$ & $4.952 \pm 0.314^{\mathrm{a}-\mathrm{c}}$ \\
$\mathrm{PA}_{2}$ & - & $7.004 \pm 0.274$ & $7.115 \pm 0.266^{\mathrm{b}}$ & $7.218 \pm 0.378^{\mathrm{b}, \mathrm{c}}$ \\
\hline
\end{tabular}

Data are expressed as mean \pm standard deviation, $\mathrm{n}=12$. ${ }^{\mathrm{a}} \mathrm{P}<0.01$ vs. $0 \mathrm{M}$; ${ }^{\mathrm{b}} \mathrm{P}<0.05$ vs. $10^{-7} \mathrm{M}$; ${ }^{\mathrm{C}}<0.05$ vs bb10 $0^{-6} \mathrm{M}$. $\mathrm{PD}_{2}, \log (50 \%$ effective concentration); $\mathrm{PA}_{2}$, intensity of competitive antagonist.

Table IV. Influence of SR59230A on the relaxant effect of isoprenaline on detrusor strip.

\begin{tabular}{lcccc}
\hline Group & $\mathrm{E}_{\max }$ & $\mathrm{IA}$ & $\mathrm{PD}_{2}$ & $\mathrm{PA}_{2}$ \\
\hline Young control & $56.06 \pm 8.66$ & $0.85 \pm 0.14$ & $5.70 \pm 0.36$ & $6.12 \pm 0.28$ \\
Model group (aging rats) & $46.02 \pm 9.52^{\mathrm{b}}$ & $0.72 \pm 0.12^{\mathrm{a}}$ & $5.37 \pm 0.22^{\mathrm{b}}$ & $6.38 \pm 0.34^{\mathrm{a}}$ \\
\hline
\end{tabular}

Data are expressed as the mean \pm standard deviation, $\mathrm{n}=12$. ${ }^{\mathrm{a}} \mathrm{P}<0.05$ and ${ }^{\mathrm{b}} \mathrm{P}<0.01$ vs. young control. $\mathrm{E}_{\max }$, effect of maximum relaxation; IA, intrinsic activity; $\mathrm{PD}_{2}, \log \left(50 \%\right.$ effective concentration); $\mathrm{PA}_{2}$, intensity of competitive antagonist.

Table V. Effect of SQW on isoprenaline-induced relaxant on detrusor strip.

\begin{tabular}{llll}
\hline Group & \multicolumn{1}{c}{$\mathrm{E}_{\max }$} & $\mathrm{IA}$ & $\mathrm{PD}_{2}$ \\
\hline Young controls & $62.69 \pm 8.23$ & $0.97 \pm 0.13$ & $6.17 \pm 0.31$ \\
Model group (aging rats) & $53.72 \pm 7.84^{\mathrm{a}}$ & $0.83 \pm 0.12^{\mathrm{a}}$ & $5.59 \pm 0.32^{\mathrm{a}}$ \\
SQW $(0.293 \mathrm{~g} / \mathrm{kg})$ & $52.26 \pm 5.52$ & $0.81 \pm 0.13$ & $5.76 \pm 0.29$ \\
SQW $(0.585 \mathrm{~g} / \mathrm{kg})$ & $59.98 \pm 7.97^{\mathrm{b}}$ & $0.97 \pm 0.08^{\mathrm{c}}$ & $5.89 \pm 0.12^{\mathrm{c}}$ \\
SQW $(1.170 \mathrm{~g} / \mathrm{kg})$ & $59.76 \pm 6.68^{\mathrm{b}}$ & $0.94 \pm 0.09^{\mathrm{c}}$ & $5.81 \pm 0.29^{\mathrm{b}}$ \\
\hline
\end{tabular}

Data are expressed as the mean \pm standard deviation, $\mathrm{n}=12 .{ }^{\mathrm{a}} \mathrm{P}<0.01 \mathrm{vs}$. young controls; ${ }^{\mathrm{b}} \mathrm{P}<0.05$ and ${ }^{\mathrm{c}} \mathrm{P}<0.01$ vs. model group. SQW, Suo Quan Wan; $\mathrm{E}_{\max }$, effect of maximum relaxation; IA, intrinsic activity; $\mathrm{PD}_{2}, \log (50 \%$ effective concentration).

Table VI. Effect of SQW on BRL37344-induced relaxant on detrusor strip.

\begin{tabular}{llll}
\hline Group & $\mathrm{E}_{\max }$ & $\mathrm{IA}$ & $\mathrm{PD}_{2}$ \\
\hline Young controls & $33.70 \pm 11.12$ & $0.50 \pm 0.17$ & $6.28 \pm 0.66$ \\
Model group (aging rats) & $24.43 \pm 7.22^{\mathrm{a}}$ & $0.36 \pm 0.11^{\mathrm{a}}$ & $5.71 \pm 0.56^{\mathrm{a}}$ \\
SQW $(0.293 \mathrm{~g} / \mathrm{kg})$ & $31.11 \pm 5.19^{\mathrm{b}}$ & $0.48 \pm 0.08^{\mathrm{b}}$ & $6.48 \pm 1.09^{\mathrm{b}}$ \\
SQW $(0.585 \mathrm{~g} / \mathrm{kg})$ & $34.16 \pm 14.08^{\mathrm{b}}$ & $0.51 \pm 0.15^{\mathrm{b}}$ & $6.36 \pm 0.43^{\mathrm{c}}$ \\
SQW $(1.170 \mathrm{~g} / \mathrm{kg})$ & $29.53 \pm 3.18^{\mathrm{b}}$ & $0.44 \pm 0.06^{\mathrm{b}}$ & $6.22 \pm 0.59^{\mathrm{b}}$ \\
\hline
\end{tabular}

Data are expressed as the mean \pm standard deviation, $\mathrm{n}=12 .{ }^{\mathrm{a}} \mathrm{P}<0.05$ vs. young controls; ${ }^{\mathrm{b}} \mathrm{P}<0.05$ and ${ }^{\mathrm{c}} \mathrm{P}<0.01$ vs. model group. SQW, Suo Quan Wan; $\mathrm{E}_{\max }$, effect of maximum relaxation; $\mathrm{IA}$, intrinsic activity; $\mathrm{PD}_{2}, \log (50 \%$ effective concentration).

SQW were able to significantly increase the MBC and VV of rats.

As shown in Fig. $1 \mathrm{G}$ and $\mathrm{H}, \mathrm{BC}$ and PVR were significantly higher in aging rats than in young controls prior to SQW administration, and no significant difference was observed between the medicine and the model groups. Following administration for 6 weeks, the three dosages of SQW exhibited no significant effect on BC. However, SQW at a high dose was able to significantly degrade PVR.
Effect of $S Q W$ on sphincter function in aging rats. As shown in Fig. 2A and B, prior to SQW administration, the MUCP and MUP in the model group were significantly lower than those in the young control group, and no significant difference was observed in the three groups of SQW. Following administration for 6 weeks, SQW at all three dosages was able to significantly increase MUCP and MUP. In addition, compared with the levels prior to administration, low-, middle- and high-dosage SQW could significantly increase the rats' MUCP and MUP. 

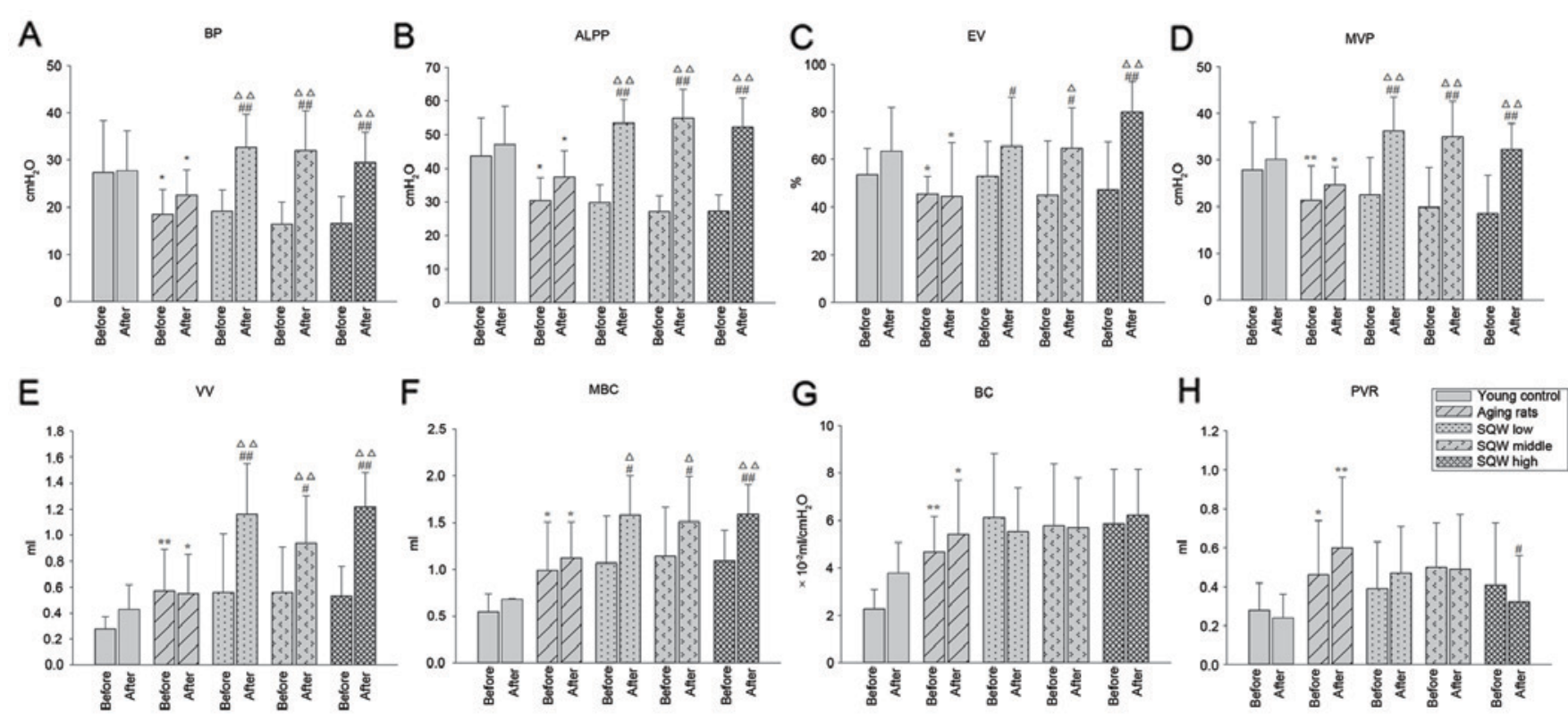

Figure 1. Effects of SQW on bladder function in aging rats are shown in the bar graphs (A-H), indicating BP, ALPP, EV, MVP, VV, MBC, BC and PVR. Data are expressed as mean \pm standard deviation and analyzed by one-way analysis of variance $(n=12) .{ }^{~} \mathrm{P}<0.05,{ }^{* *} \mathrm{P}<0.01$ vs. young controls; ${ }^{*} \mathrm{P}<0.05,{ }^{\# \#} \mathrm{P}<0.01 \mathrm{vs}$. model group; ${ }^{\wedge} \mathrm{P}<0.05,{ }^{\Delta} \mathrm{P}<0.01$ vs. before administration in the same group. SQW, Suo Quan Wan; BP, bladder leak point pressure; ALPP, abdomen leak point pressure; EV, efficiency of voiding; MVP, maximum voiding pressure; VV, voiding volume; MBC, maximum bladder capacity; BC, bladder capacity; PVR, post-void residual.

A

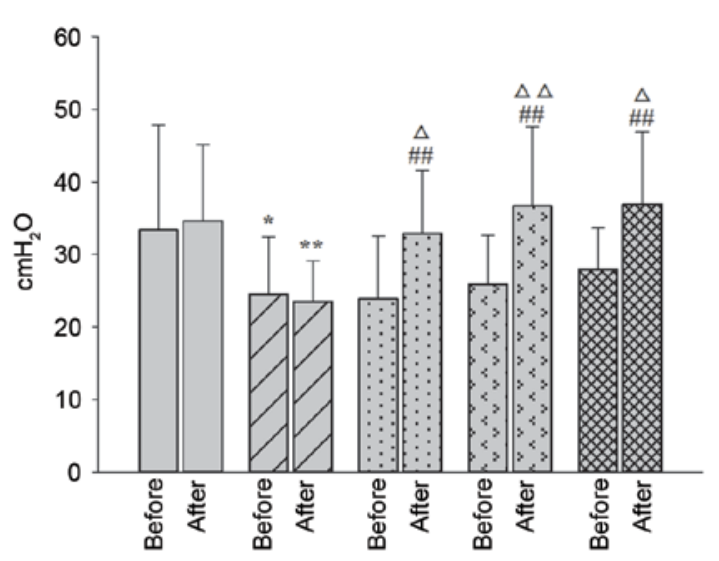

C

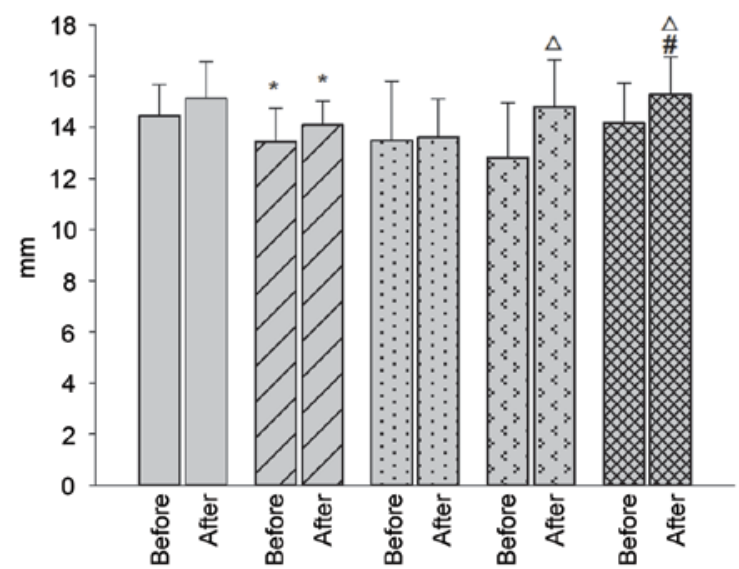

B

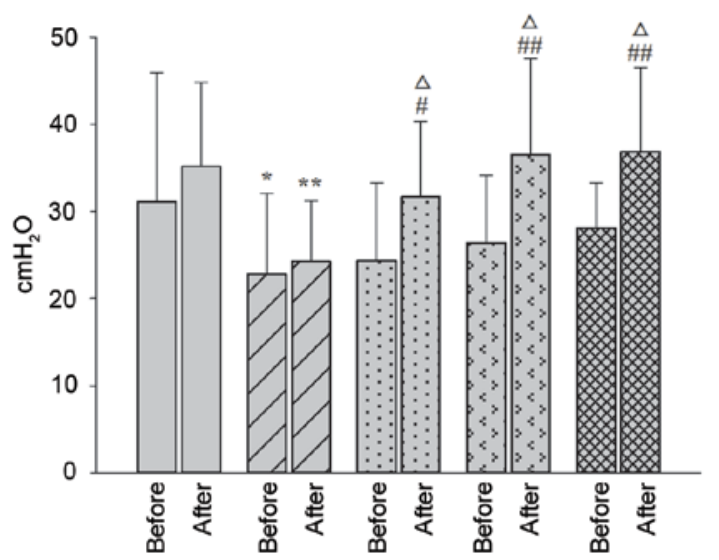

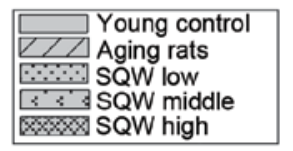

Figure 2. Effects of SQW on sphincter in aging rats are shown in the bar graphs (A-C) indicating MUCP, MUP, and FUL. Data are expressed as mean \pm standard deviation and analyzed by one-way analysis of variance $(\mathrm{n}=12) .{ }^{*} \mathrm{P}<0.05,{ }^{* *} \mathrm{P}<0.01$ vs. young control; ${ }^{\#} \mathrm{P}<0.05,{ }^{\# \#} \mathrm{P}<0.01$ vs. model group; ${ }^{\Delta} \mathrm{P}<0.05,{ }^{\Delta \Delta} \mathrm{P}<0.01$ vs. before administration in the same group. SQW, Suo Quan Wan; MUCP, maximum urethral closure pressure; FUL, functional urethral length. 
Table VII. Effect of SQW on SR59230A-induced inhibition on detrusor strip.

\begin{tabular}{lc}
\hline Group & $\mathrm{PA}_{2}$ \\
\hline Young controls & $6.12 \pm 0.28$ \\
Model group (aging rats) & $6.38 \pm 0.34^{\mathrm{a}}$ \\
SQW $(0.293 \mathrm{~g} / \mathrm{kg})$ & $6.46 \pm 0.29$ \\
SQW $(0.585 \mathrm{~g} / \mathrm{kg})$ & $6.10 \pm 0.32^{\mathrm{b}}$ \\
SQW $(1.170 \mathrm{~g} / \mathrm{kg})$ & $5.89 \pm 0.62^{\mathrm{b}}$ \\
\hline
\end{tabular}

Data are expressed as the mean \pm standard deviation, $\mathrm{n}=12$. ${ }^{\mathrm{a}} \mathrm{P}<0.05$ vs. young controls; ' $\mathrm{P}<0.05$ vs. model group. SQW, Suo Quan Wan; $\mathrm{PA}_{2}$, intensity of competitive antagonist.

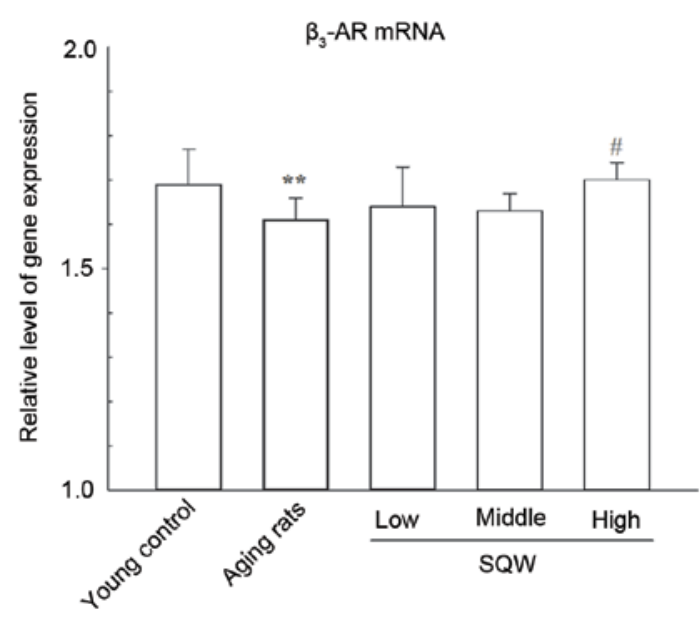

Figure 3. Effects of SQW on $\beta_{3}$-AR mRNA expressions. Data are expressed as mean \pm standard deviation and analyzed by one-way analysis of variance $(\mathrm{n}=12) .{ }^{* *} \mathrm{P}<0.01$ vs. young control; ${ }^{*} \mathrm{P}<0.05$ vs. model group. SQW, Suo Quan Wan; AR, adrenoceptor.

As shown in Fig. 2C, prior to SQW administration, the FUL of the model group was significantly lower than that of young controls, and no significant difference was found from that in the SQW groups. Following SQW administration for 6 weeks, high-dosage SQW significantly increased the rats' FUL in comparison with the model group. In addition, the FUL of rats increased significantly following administration of SQW at middle and high dosages compared with levels prior to SQW administration.

Expression of $\beta_{3}-A R$ mRNA. As shown in Fig. 3, following SQW administration the expression of $\beta_{3}$-AR mRNA in the model group was significantly lower than that in the young control group. Furthermore, SQW at a high dosage was able to significantly increase the $\beta_{3}$-AR mRNA expression.

\section{Discussion}

Due to the side effects of modern pharmacological agents and therapies developed in recent years, the use of natural plants for treatment of LUTS is gaining increasing importance worldwide. The incidence of voiding dysfunction is reported to be $15-30 \%$ in people $>60$ years old and is associated only with age (29). The majority of relevant studies suggest that the cholinergic receptor and $\beta$-AR are the most important receptors in bladder function (30-32). With increasing age, the number and affinity of the MR hardly change. Therefore, bladder dysfunction is primarily associated with the change in $\beta$-AR (33). A number of clinical and experimental studies have demonstrated that $\beta_{3}$-AR serves an important role in this process (34). This conclusion was also proven according to the result of qPCR, which revealed higher expression of $\beta_{3}$-AR compared with $\beta_{1}$-AR and $\beta_{2}$-AR ( $\left.\beta 1: \beta 2: \beta 3 \approx 1: 1: 70\right)$ found in the bladder detrusor $(35,36)$.

In the first part of the present study, the differences in the neurogenic changes between young and aging rats were explored. The influence of the $\beta$-AR non-selective agonist, subtype $\beta_{3}$-AR agonist and subtype $\beta_{3}$-AR antagonist was also studied. In addition, the changes in the $\beta$-AR and subtype $\beta_{3}$-AR in aging rats were detected.

The $\beta_{3}$-AR and $\beta$-AR in the rat bladder were able to relax the detrusor, and the subtype $\beta_{3}$-AR had the most notable role within $\beta$-AR (37). With increasing concentration, ISO, the $\beta$-AR agonist, and BRL37344, the subtype $\beta_{3}$-AR agonist, exhibited increasing inhibition to the contraction of the detrusor strip as induced by $\mathrm{KCl}$. The $\mathrm{E}_{\max }$ and IA values of BRL37344 were lower than those of ISO, but no significant difference was observed in $\mathrm{PD}_{2}$, indicating that the content of $\beta_{3}$-AR was almost equivalent to that of $\beta$-AR. Compared with BRL37344, ISO revealed a significant effect on the relaxation of the detrusor. With increasing concentration, SR59230A exhibited an increasingly distinct blocking action on the relaxant effect caused by ISO, in turn causing $\mathrm{E}_{\max }$, IA and $\mathrm{PD}_{2}$ to decrease.

The relaxant role of the $\beta$-AR in the detrusor of aging rats declined mainly because of the decline in $\beta_{3}$-AR. Furthermore, the relaxant functions of the $\beta$-AR and the subtype $\beta_{3}$-AR agonist in model animals diminished (expressed as the decline in $\mathrm{E}_{\max }$ and IA, and the decrease in $\mathrm{PD}_{2}$ ) compared to young animals. In addition, the $\beta_{3}$-AR antagonist had a smaller effect in affecting the detrusor in aging compared to young animals.

The change in the $\beta$-AR was also reflected in vivo with the BP, ALPP, FUL, MUP and MUCP levels all decreasing in aging rats. This observation indicates that the urine storing function of the bladder weakened, and it is consistent with bladder detrusor relaxation dysfunction caused by a decrease in $\beta$-AR.

In the second part of the present study, the effect of SQW on an aging rat bladder and $\beta_{3}$-AR was tested. The causes of LUTS in elders were closely linked with a urodynamic problem, which is a well-recognized objective evaluation path to diagnosing LUTS (38).

In the in vitro test, the bladder detrusor showed a greater sensitivity to the relaxation effect of ISO and BRL37344 following treatment with $\mathrm{SQW}$, given that $\mathrm{E}_{\max }$, IA and $\mathrm{PD}_{2}$ all increased. In addition, SQW was able to increase the effect of the $\beta_{3}$-AR antagonist SR59230A, which inhibits ISO relaxation and decreases $\mathrm{PA}_{2}$. The results indicate that $\mathrm{SQW}$ was able to improve the $\beta$-AR function by relying on its effect on $\beta_{3}$-AR.

The functional state of bladder storage is associated with BP, ALPP, MBC and BC. The MVP, PVR and EV appear to be the main factors to consider in the study of the function 
of bladder voiding. However, FUL, MUP, and MUCP are the critical indicators of the status of urinary continence. In brief, leaking and nocturia are associated with storing, voiding and urinary continence functions of the bladder (39).

SQW was able to significantly improve the urinary continence state by improving the contractile function of the urethral sphincter and the diastolic function of the smooth muscle, including the improvement of urinary continence by raising animal BP, ALPP, MUP, FUL and MUCP levels. Furthermore, SQW was also able to increase bladder MBC via further relaxation of the bladder in order to improve urine storage.

In aging animals, SQW was able to distinctly improve the urinary function by boosting the aging animal's MVP and VV, increasing its EV and decreasing its PVR following urination, which may be achieved by improving the detrusor's contractile function during urination. Therefore, SQW was able to improve the aging animal's bladder contraction.

Based on the results of the urodynamic test, SQW was able to improve LUTS in the aging animal by improving the closing dysfunction of the urethral sphincter and relaxing the bladder during urination to boost the bladder function of urine storage and to improve uroclepsia. In addition, SQW was able to increase bladder micturition pressure to stimulate urination and to improve the states of incomplete urination and urination weakness. Furthermore, it was able to improve frequent urination by extending the micturition period.

A previous study used young Sprague-Dawley rats to define the therapeutic effect of SQW on an overactive bladder (40). This implies that young adult rats may also receive the treatment of SQW and that there are not any contraindications. However, the effect of SQW on normal young rats remains uncertain and further experiments should be carried to illustrate this issue. In conclusion, the decrease in $\beta$-AR sensitivity and expression in aging rats resulted in bladder detrusor relaxation dysfunction and a decrease in bladder capacity. In addition, the SQW formula was shown to possess a therapeutic effect against LUTS. The present study demonstrated that the therapeutic effect of SQW may be mediated by the increase in urethral sphincter contraction and micturition efficiency and a relaxed bladder detrusor, and that $\beta_{3}$-AR may be one of the targets of the effect of SQW.

\section{Acknowledgements}

The present study was supported by the National Science Foundation of China (grant no. 81202982), Educational Finance Grant [grant no. 276 (2014)] and the Research Fund for the Doctoral Program of Higher Education of China (grant no. 20124425110006)

\section{References}

1. Fultz NH, Burgio K, Diokno AC, Kinchen KS, Obenchain R and Bump RC: Burden of stress urinary incontinence for community-dwelling women. Am J Obstet Gynecol 189: 1275-1282, 2003.

2. Oelke M, Baard J, Wijkstra H, de la Rosette JJ, Jonas U and Höfner K: Age and bladder outlet obstruction are independently associated with detrusor overactivity in patients with benign prostatic hyperplasia. Eur Urol 54: 419-426, 2008.
3. Luo GC, Fang Q, Li LK, Jin XY and Song B: Urodynamic characteristics of stress urinary incontinence occurred in premenopausal and postmenopausal adult women. Zhong Guo Kang Fu Li Lun Yu Shi Jian 12: 523-524, 2006 (In Chinese).

4. Hirai K, Sumi T, Kanaoka Y and Ishiko O: Female urinary incontinence: Diagnosis, treatment and patients' concerns. Drugs Today (Barc) 38: 487-493, 2002.

5. Esin E, Ergen A, Cankurtaran M, Yavuz BB, Halil M, Ulger Z, Yeşil Y, Kuyumcu ME, Ozcan M, Cankurtaran E and Ariogul S: Influence of antimuscarinic therapy on cognitive functions and quality of life in geriatric patients treated for overactive bladder. Aging Ment Health 19: 217-223, 2015.

6. Nishimoto T, Latifpour J, Wheeler MA, Yoshida M and Weiss RM: Age-dependent alterations in beta-adrenergic responsiveness of rat detrusor smooth muscle. J Urol 153: 1701-1705, 1995.

7. Zhao XH, Xiong EQ, Song B and Qiu JH: Neurogenic mechanism of alteration in relaxation function of urinary bladder detrusor in aging rats. Hua Bei Guo Fang Yi Yao 16: 36-37, 2004 (In Chinese).

8. Clouse AK, Riedel E, Hieble JP and Westfall TD: The effects and selectivity of beta-adrenoceptor agonists in rat myometrium and urinary bladder. Eur J Pharmacol 573: 184-189, 2007.

9. Deba A, Palea S, Rouget C, Westfall TD and Lluel P: Involvement of beta(3)-adrenoceptors in mouse urinary bladder function: Role in detrusor muscle relaxation and micturition reflex. Eur J Pharmacol 618: 76-83, 2009.

10. Yamaguchi $\mathrm{O}$ and Chapple CR: Beta3-adrenoceptors in urinary bladder. Neurourol Urodyn 26: 752-756, 2007.

11. Lan SG: 78 cases of pediatric enuresis treated with ootheca mantis powder, suoquan Pill and acupuncture. Zhong Yi Er Ke Za Zhi 8: 46-47, 2012 (In Chinese).

12. Yu MY and Li X: 52 cases of infantile enuresis treated with modified Suoquan Pill combined with transdermal drug delivery. J Pediatr TCM 8: 51-52, 2012 (In Chinese).

13. Mao Y and Dai XJ: Observations on the efficacy of Suoquan Decoction in treating deficiency of kidney-yang and NUTI in the elderly of 30 cases. Zhong Yi Er Ke Za Zhi 27: 31, 2013.

14. Xie C, Xie GM, Li JH and Zhou L: Combination of 'Suoquan Capsule' and western medicine for the treatment of chronic prostatitis of kidney-yang deficiency pattern. Shang Hai Zhong Yi Yao Za Zhi 48: 47-49, 2014 (In Chinese).

15. Cao HY, Wu QH, Huang P and He JY: Impacts of the formula of Suoquanwan(SQW) on expression of AQP-2 mRNA and AVPR-V2 mRNA in the kidney of rat polyuria model of Yang-deficiency. Zhong Yao Cai 32: 926-928, 2009 (In Chinese).

16. Cao HY, Wu QH, Huang P and He JY: Impacts of the formula of suoquanwan on expression of CAMP and ALD in the blood of rat polyuria model of yang-deficiency. Xin Zhong Yi 41: 101-102, 2009 (In Chinese).

17. Committee CP (ed): Pharmacopoela of People's Republic of China. 4th ed. China Medical Science Press, Beijing, p5, 2010.

18. Liang ZJ, Jiang WW, Cao HY, et al: Study on qualification standard of Suoquan Pill. Zhong Yao Xin Yao Yu Lin Chuang Yao Li 2: 236-239, 2015 (In Chinese).

19. Wei W, Ximei W and Yuanjian L (eds): Equivalent dose calculation method In: Experimental Methodology of Pharmacology. 4th editon. People's Medical Publishing House, Beijing, p4, 2010.

20. Li G, Zheng XH, Li K, Li ZH, Luo XD, Liu YL and Wang P: Age-dependent alternations in beta-adrenoceptor function in human detrusor and possible mechanism. Zhonghua Wai Ke Za Zhi 41: 526-529, 2003 (In Chinese).

21. Takeda M, Obara K, Mizusawa T, Tomita Y, Arai K, Tsutsui T, Hatano A, Takahashi K and Nomura S: Evidence for beta3-adrenoceptor subtypes in relaxation of the human urinary bladder detrusor: Analysis by molecular biological and pharmacological methods. J Pharmacol Exp Ther 288: 1367-1373, 1999.

22. Tasler S, Baumgartner R, Ammendola A, Schachtner J, Wieber T, Blisse M, Rath S, Zaja M, Klahn P, Quotschalla U and Ney P: Thienopyrimidines as $\beta 3$-adrenoceptor agonists: Hit-to-lead optimization. Bioorg Med Chem Lett 20: 6108-6115, 2010.

23. Otsuka A, Shinbo H, Hasebe K, Matsumoto R and Ozono S: Effects of a novel beta(3)-adrenoceptor agonist, AJ-9677, on relaxation of the detrusor muscle: An in vitro study. Int $\mathrm{J}$ Urol 15: 1072-1076, 2008.

24. Luo XX, Chai YB and Tan YH: A simplified method for calculating pA2 and pD2. Di Si Jun Yi Da Xue Xue Bao 11: 136-139, 1999 (In Chinese).

25. Xiulan H: The measurement of PD2 and PA2. Chuan Bei Yi Xue Yuan Xue Bao 4: 61-63, 1995 (In Chinese). 
26. Kuang ZJ, Cao HY, Huang $\mathrm{P}$ and $\mathrm{Wu} \mathrm{QH}$ : Comparison of urodynamical differences by two cystometric methods in rats of different ages. Zhong Guo Yao Li Xue Tong Bao 28: 581-583, 2012.

27. Damaser MS, Kim FJ and Minetti GM: Methods of testing urethral resistance in the female rat. Adv Exp Med Biol 539: 831-839, 2003.

28. Livak KJ and Schmittgen TD: Analysis of relative gene expression data using real-time quantitative PCR and the 2(-Delta Delta C(T)) method. Methods 25: 402-408, 2001.

29. Park YC, Tomiyama Y, Hayakawa K, Akahane M, Ajisawa Y, Miyatake R, Kiwamoto H, Sugiyama T and Kurita T: Existence of a beta3-adrenoceptro and its functional role in the human ureter. J Urol 164: 1364-1370, 2000 .

30. Andersson KE and Arner A: Urinary bladder contraction and relaxation: Physiology and pathophysiology. Physiol Rev 84: 935-986, 2004.

31. Michel MC and Vrydag W: Alpha1-, alph2- and beta-adrenoceptor in the urinary bladder, urethra and prostate. Br J Pharmacol 147 (Suppl 2): S88-S119, 2006

32. Takeda H, Yamazaki Y, Akahane M, Igawa Y, Ajisawa Y and Nishizawa O: Role of the beta(3)-adrenoceptor in urine storage in the rat: Comparison between the selective beta(3)-adrenoceptor agonist, CL316, 243, and various smooth muscle relaxants. J Pharmacol Exp Ther 293:939-945, 2000 .

33. Kaplan EP, Richier JC, Howard PS, Ewalt DH and Lin VK: Type III collagen messenger RNA is modulated in non-compliant human bladder tissue. J Urol 157: 2366-2369, 1997.
34. Roosen A, Blake-James BT, Wood D and Fry CH: Clinical and experimental aspects of Adreno-muscarinic synergy in the bladder base and prostate. Neurourol Urodyn 28: 938-943, 2009.

35. Morris AJ and Malbon CC: Physiological regulation of G protein-linked signaling. Physiol Rev 79: 1373-1430, 1999.

36. Yamaguchi O: Beta3-adrenoceptors in human detrusor muscle. Urology 59 (5 Suppl 1): S25-S29, 2002.

37. Fujimura T, Tamura K, Tsutsumi T, Yamamoto T, Nakamura K, Koibuchi Y, Kobayashi M and Yamaguchi O: Expression and possible functional role of the beta3-adrenoceptor in human and rat detrusor muscle. J Urol 161: 680-685, 1999.

38. Dalkin BL, Wessells $\mathrm{H}$ and Cui H: A national survey of urinary and health related quality of life outcomes in men with an artificial urinary sphincter for post-radical prostatectomy incontinence. J Urol 169: 237-239, 2003.

39. Laniado ME, Ockrim JL, Marronaro A, Tubaro A and Carter SS: Serum prostate-specific antigen to predict the presence of bladder outlet obstruction in men with urinary symptoms. BJU Int 94: 1283-1286, 2004.

40. Lai H, Tan B, Liang Z, Yan Q, Lian Q, Wu Q, Huang P and Cao H: Effect of the Chinese traditional prescription Suo Quan Wan on TRPV1 expression in the bladder of rats with bladder outlet obstruction. BMC Complement Altern Med 15: $424,2015$. 